بررسى تجمع و جذب فلزات سنگين توسط كاهو در يك خاك تيمار شده با ضايعات معدنى كارخانجات سرب و روى

زهرا رجبى'، يريسا علمدارى 'و احمد كلجين'

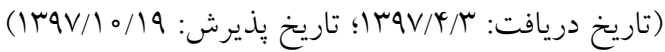

جكيده

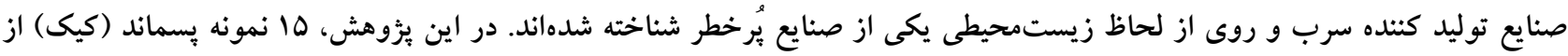

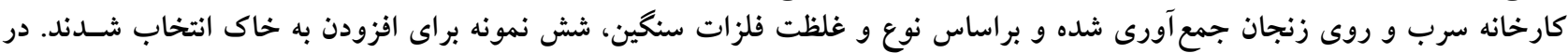

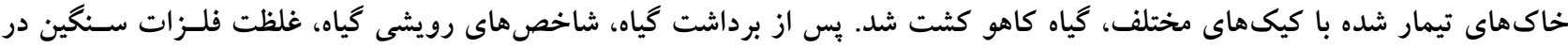

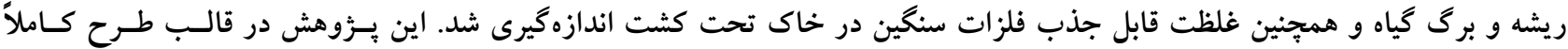

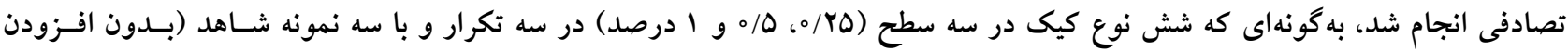

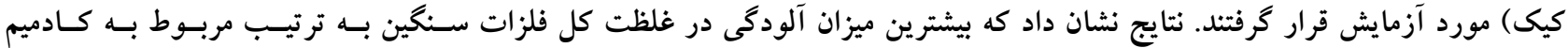

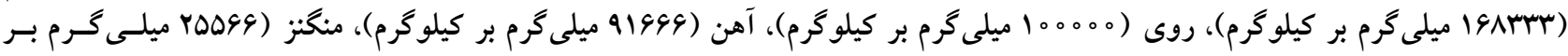
كيلو ميلى (194 ميلى جذب توسط كياه كاهو در خاك كاهش يافت اهن

كلمات كليدى: بسماند كارخانجات ذوب سرب و روى، فلزات سنگين، كيك، قابليت جذب

اين گياه براى مطالعه حاضر انتخاب شد.

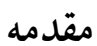

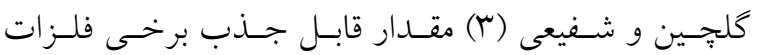

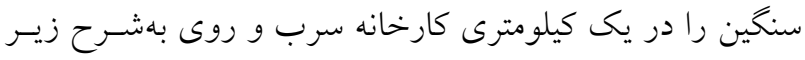
يُزوهشهاى متعدد نشان داده كه كاهو قادر است مقــدار زيـادى

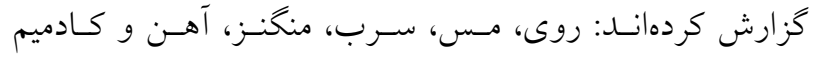

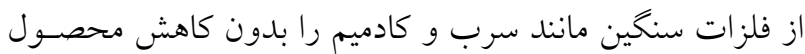

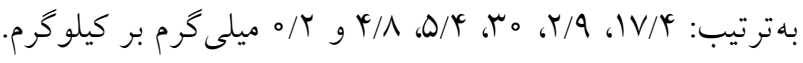
و يا نشان دادن آثار مسموميت جذب كند (Yr). با توجه به ايسن موضوع و همجنين نقش مهم كاهو در رزيم غذايى مردم ايـران، 
اهميــت بيشـترى نسـبت بــه محتــواى كـل فلــز، در قابليـت

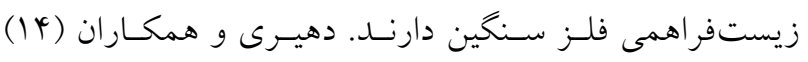
عنوان كردنـــ كـه كـادميم باعـث كـاهش معنسى دارى در وزن خشك اندام هوايى اسفناج شد. ميـزان ايسن كـاهش در خـاك

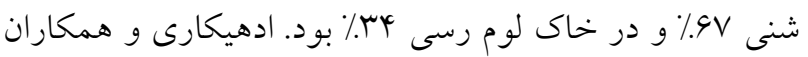
كزارش كردند كه در برنج، با افزايش كـادميم بـه محلـول غذايى، مقدار عملكرد و كلروفيـل بـرى هــا كـاهش مسى يابــ. همجنين، افزايش جذب كادميم بهوسيله بـرنج باعـث كـاهش

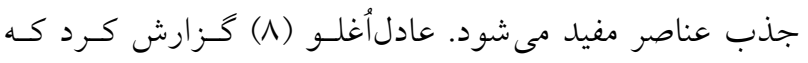
مصرف روى در گياهان گنــدم، جـو، ذرت و يـولاف، غلظـت كادميم را كاهش داده است. اين نتايج نشـان مسى دهـد كـه در خاكهاى با كمبود روى، كادميم در گياه تجمـع مسى يابــ. امـا حضور روى در خاى مانع اين تجمع مى شود. همجنين، بودار و همكاران (سT) بر طبق آزمايشى كه روى كياه اسفناج انجـام دادند گزارش كردند كه سلامتى انسان با مصرف گياهان رشـد

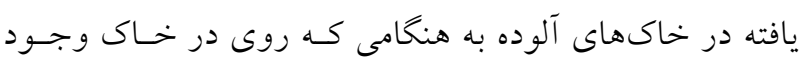
دارد كمتر بهنطر مى افتد. يزّوهشهاى اندكى در زمينه بررسى زيست فر اهمسى فلـزات سنخين موجـود در يسـماندهاى معـدنى ايسن صـنايع در سـطح كشور انجام شده است. در اين بئوهش، بررسى زيست فراهمى

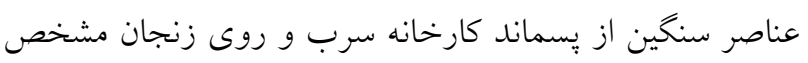

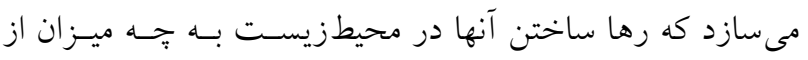
لحاظ كياهجذبى و ورود فلزات سنخين به جرخه غـذايى انسـان خطرساز است و كدام فلز سنخين خطر بيشـترى بـراى سـالامتى

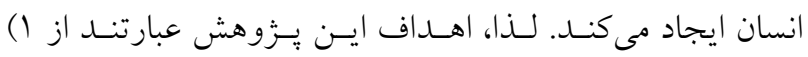

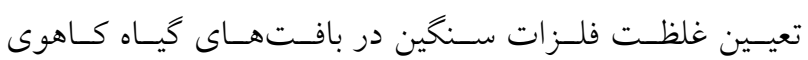
يرورش يافتـه در خـاكهــاى تيمـار شــه بـا ضـايعات معـدنى كارخانجـات سـرب و روى زنجــان و r) بررسـى ارتبـاط بـين غلظت هاى كل و قابل جذب فلزات سنخين خـاك بـا غلظـت و مقدار جذب شده آنهـا توسـط كيـاه كـاهو. اسـتفاده از يسـماند طبيعى كارخانه سرب و روى زنجان براى آلوده كردن خاكها و بررسى گياهفراهمى از كيكها نو آورى يزوهش حاضر است.
يسماندهاى صـنايع سـرب و روى حساوى مقـادير بسـيار زيـاد كادميم، سرب، نيكل و آرسنيك هستند و اخر اين بِّسماندها در لِّر آب هاى سطحى رها شوند در سـطح وسـيعى از منطقـه يخـش

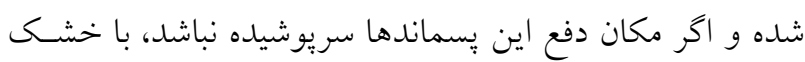
شدن و تشكيل غبار، امكان بخش اين آلـودكى هـا وجـــود دارد. كردوغبــار متصـاعد شــده از دودكـشهــا و فرونشسـت ايسن

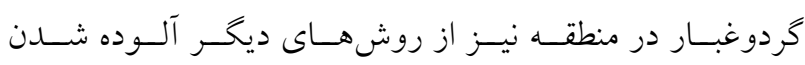
محيطزيست است. با دفع غير اصولى بـمماندهاى توليد شـده در

سطح منطقه، منابع خاك به فلزات سنخين آلوده مىشود (ه).

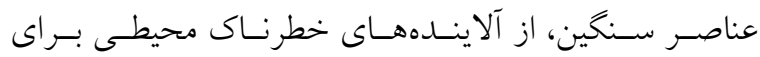
سلامتى بشر و محيطزيست محسـوب مسىشـوند. ايسن عناصـر مى توانند بر كيفيت خاكهاى كشاورزى اثركذار بوده و از طريق جذب توسط گياهان و ورود به جرخه غذايى بشر سـبب بـروز مشكالتى براى سلامتى انسان شوند (IV). ورود فلزات سنخين به زنجيره غذايى بيامدهاى نامطلوبى را

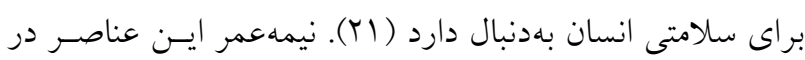
بدن بسيار طولانى است و در بافتهاى زنده براى مدت طولانى باقى مىمانند (T) (I). روى و سرب عناصرى هستند كـه بيشـترين مقـدار فلـزات

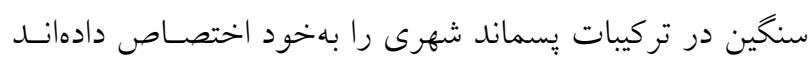
(YN) (YN) شرفبافى و شهبازى (Y) در يزوهشى، اثر غلظـت و زمـان را بر زيستفراهمى كادميم و سرب افزوده شده بـه يـك خـاك اسيدى و سه خاك قليايى مورد بررسى قرار دادند. نتسايج نشـان داد كه تغييرات زيستفراهمى كادميم و سـرب در ابتـدا شـديد بود و سبس كند مىشد. سومار و همكاران (Y9)، مشاهده كردند كه ميزان روى محلول در آب در بستر حاوى زغالسنگ نـارس نسبت به كميوست يُماندهاى زيستى بيشتر بود. ايسن درحسالى بود كه محتواى كل روى در زغالسنگ نارس (4 أl ميلى گرم بر

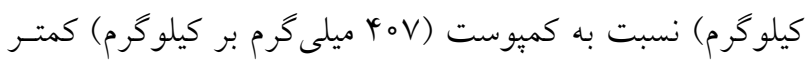
بود. علت اين موضوع به كـم بـودن pH در بسـتر زغـالسـنگ نارس (pH=Q/ه) نسـبت بـه كميوسـت (pH=V/T) نسـبت داده شد. بنابراين، بهنظر مىرسد كه ويزگى ها شـيميايى بقايـاى آلى 


\begin{tabular}{|c|c|c|c|c|c|c|}
\hline ليج & منغخنز & ليج معمولى & منخنز يرعيار & نيكل & ليج يرعيار & \\
\hline \multicolumn{6}{|c|}{ ميلى كرم بر كيلو ررم } & \\
\hline IOFNT & 11000 & 91994 & lOGMT & $10 V 0$ & TrYAT & آهن كل \\
\hline 11 & $9 / 49$ & $9 / 0$ & $D / K Y$ & $r / \mu \Lambda$ & N/VG & آهن قابل جذب \\
\hline 199 & TYqm & $r \circ r$ & TODSG & $9 \wedge 9$ & $\Delta \vee \wedge$ & منخنز كل \\
\hline$\varphi / \circ 0$ & 490 & $r / 4$ & YIYOO & $1 T / 49$ & $r \Delta / 9$ & منخنز قابل جذب \\
\hline M Mag & 94 & 1919 & سMט & 900 & $\mid M Y A$ & سرب كل \\
\hline pr & $1 / 19$ & rrVI & N/Y & $\varphi / M$ & 4 & سرب قابل جذب \\
\hline Y०००० & 100000 & $\Lambda T Q \circ \circ$ & 10000 & $Y Q 0 \circ \circ$ & 10000 & روى كل \\
\hline$\Delta \circ \circ$ & $9 V 00$ & 190 & rloo & 19400 & $11 \circ 0$ & روى قابل جذب \\
\hline 109 & r.l & 1191 & 900 & سחس19N1 & 411 & كادميم كل \\
\hline $\mathrm{rq} / \mathrm{\Lambda}$ & rA。 & $\varphi_{0}$ & $r \circ r$ & YOT. & let & كادميوم قابل جذب \\
\hline 49 & YII & 119 & 114 & 1999 & 114 & نيكل كل \\
\hline$\Delta / \Gamma$ & 10 & $0 / 4 r$ & $9 / 79$ & 194 & $K Y / l$ & نيكل قابل جذب \\
\hline
\end{tabular}

\section{كشت در كلخانه}

مواد و روشها جمع آورى كيكها و نمونهبردارى از خاكها تعداد ها نمونه يسماند (كيك) از كارخانه سرب و و روى جادهاه

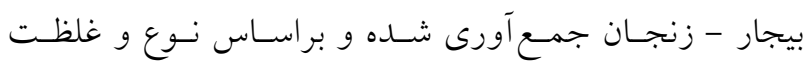

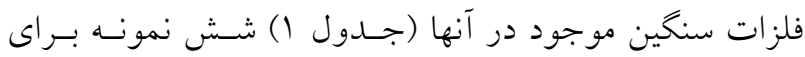

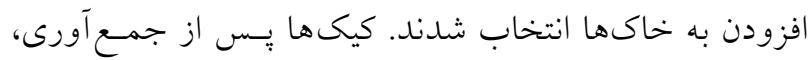

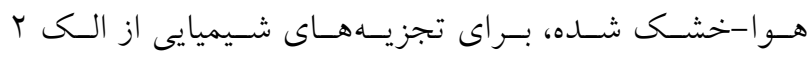

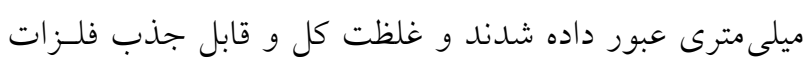

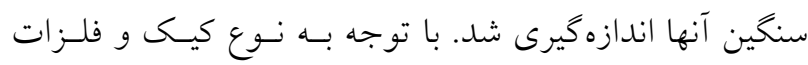

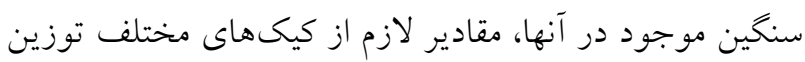

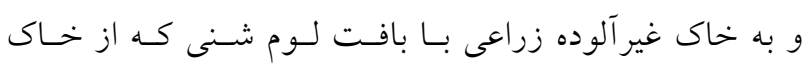

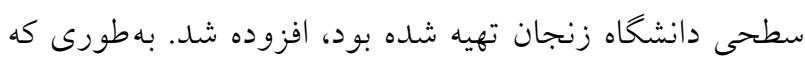

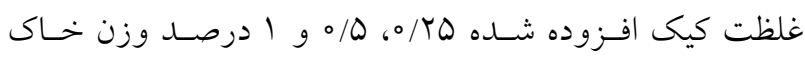

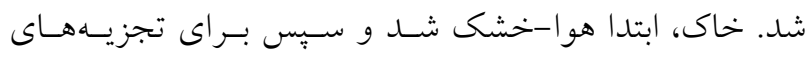

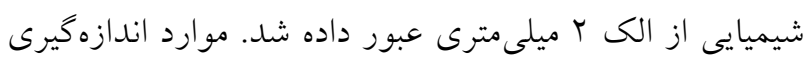

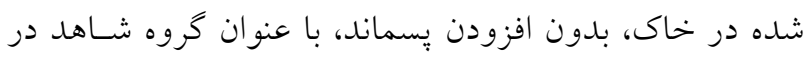

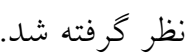


جدول Y. برخى ويزگى هاى فيزيكى و شيميايى خاك مورد مطالعه

\begin{tabular}{|c|c|c|c|c|c|c|c|c|}
\hline $\begin{array}{c}\mathrm{EC} \\
(\mathrm{dS} / \mathrm{m})\end{array}$ & $\mathrm{pH}$ & ظرفيت زراعى & كربن آلى & كربنات كلسيم & (\%) & سيلت & شن & بافت خاك \\
\hline$\circ / 4 \Delta \circ$ & $V / V$ & $1 \mathrm{~V} / 0$ & $0 / M Y$ & $1 Y / 0$ & 19 & YI & س & لوم شنى \\
\hline
\end{tabular}

باشد. اين مطلب همسو با يافته هاى همفيل (0 إست كه عنوان

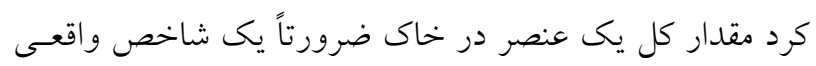
از مقدار قابل جذب آن براى گياه نيست. وقـوع سـمّيت فلـزات براى كياهان و ريزجاندارانهاى خاى يا مقادير زياد انتقـال آنهـا به زنجيره غذايى، به زيسـتفراهمى فلـز مـرتبط اسـت. جـزء

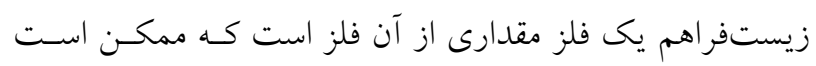
بهوسيله كياهان يا جاندار ان خاك جذب شـود. مقـدار كـل فلـز مركب از اجزايى است كه حلاليت و قابليـت اسـتفاده متفـاوتى دارند. زيست فراهمى فلز به رفتـار شـيميايى فلـز، ويزخى هــاى خاى و ويز گیىهاى اختصاصى گيرندهها (جانـداران و گياهـان)

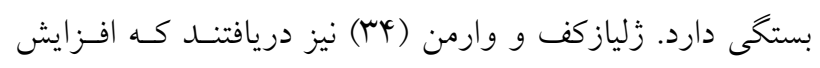
غلظت عناصر در بافتهاى گياهى، متناسب با غلظت كل فلزات خاى تيمار شده با كميوست حاوى فلزات نبود.

\section{اثر تيمارهاى مورد مطالعه بر مقدار فلزات در ريشه و برگ} نتايج تجزيه واريانس تأثير تيمارهاى مختلف بر غلظـت فلـزات در ريشه و برى نشان مى دهد كه اختلاف معنسى دارى از لحساظ غلظت كادميم، آهن، منخگـز، نيكـل، سـربـ و روى در ريشـهـ و

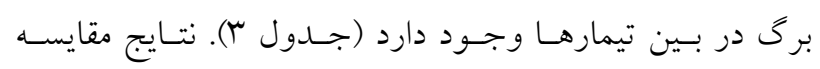
ميانگين تأثير تيمارهاى مختلف بر غلظت كادميم ريشه نشان داد

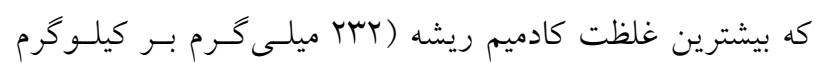
وزن خشك) در تيمار (\% كيك نيكل و كمترين غلظـت كـادميم

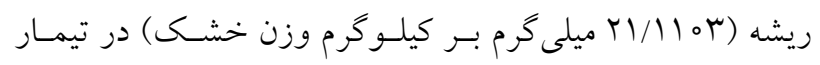
شاهد وجود دارد (جدول †). در ميان فلـزات سـنخين، كـادميم بهراحتى بهوسيله ريشه گياهان جذب مىشود و سمّيت آن براى كياه تا هب برابر ساير فلزات سنخين است. الكساندر و همكـاران (9) و همجنين خداوردى لو و همايى (1) در آزمايش هاى خود
منكنز، نيكل، سرب و روى) در خاى و كيكها از روش هضـم تر با اسيد (1) و (1) براى اندازه كيرى غلظت قابـل جـــب فلـزات

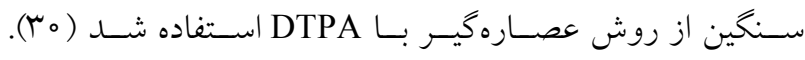

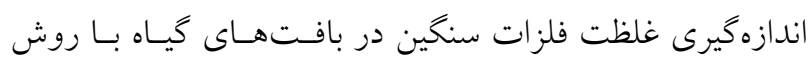
هضم مرطوب (Yr) انجام شد.

\section{تجزيه و تحليل دادهها}

اين يزوهش در قالب طرح كاملاً تصادفى انجام شد. بـهـونسهاى

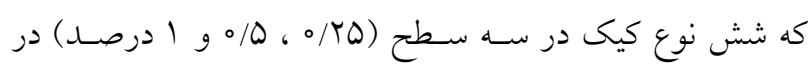

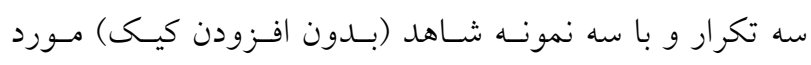

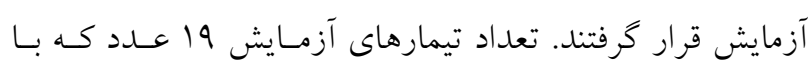

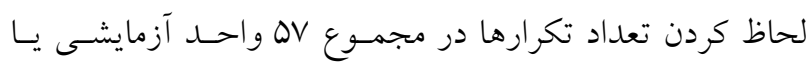

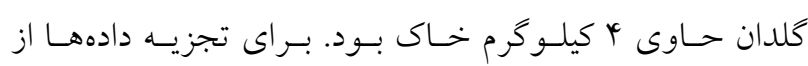
نرمافزار آمارى SPSS استفاده شد و مقايسه ميـانخين تيمارهـاى كئس

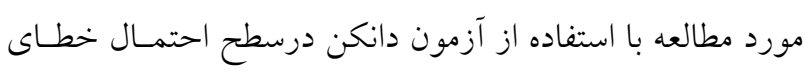

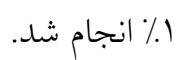

نتايج و بحث ويزگى هاى فيزيكى و شيميايى خاك مورد استفاده در آزمـايش، يبش از اعمال تيمارها، در جدول (Y) نشان داده شده است. در اين آزمايش، رابطه خطى بـا ضـرايب تبيـين متفـاوتى ميـان غلظت كل و غلظت قابل جـــب فلـزات سـنخين گونـاگون در يسماندها مشاهلده شد (شكل (). از بـين فلـزات بررسىى شـلهه،

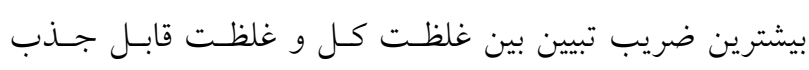
مربوط به كادميم و نيكل بهترتيب 99/ ه و 19 ه بود. اين نتيجسه مشخص مى كند كه نمونهاى كه غلظت كل زيادى از فلز را دارد حتماً نمى تواند غلظت زياد قابل جذب همان فلز را هـم داشـته 

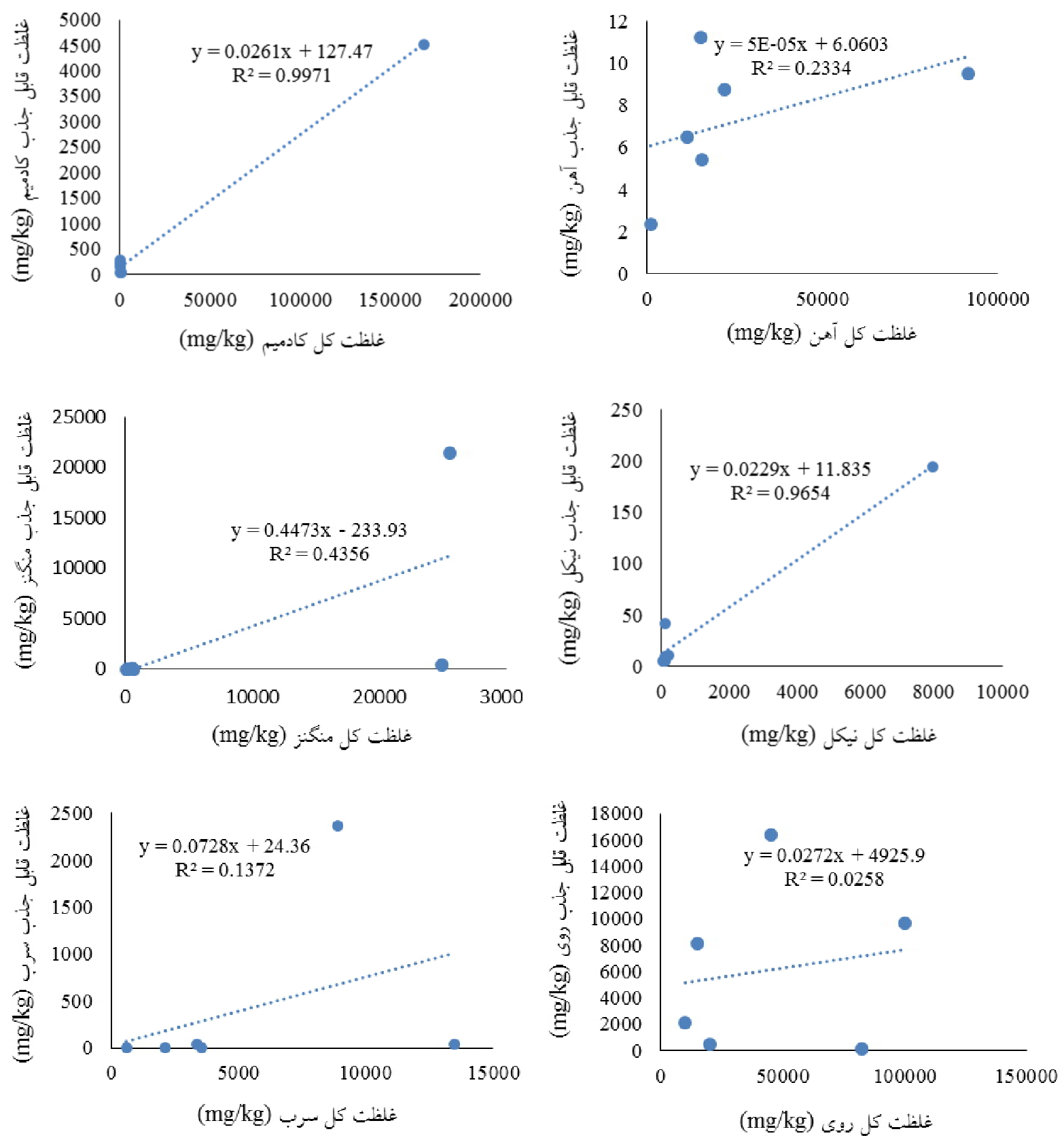

شكل ا. روابط خطى بين غلظت كل و غلظت قابل جذب عناصر مورد مطالعه در بِماندها

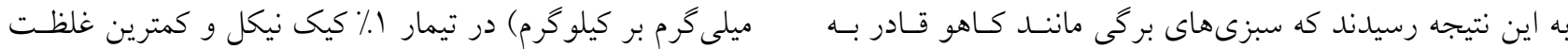

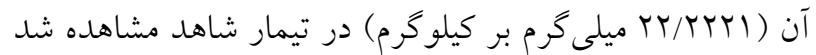
استخراج مقادير قابل توجهى از سرب و كادميم هستند.

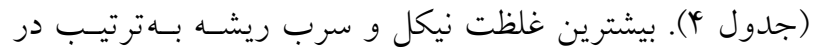
بيشترين غلظت آهن ريشه در تيمار 1/ كيى ليج معمولى و تيمار 1\% كيك نيكل و تيمار 1\% كيكى ليتج و كمتـرين غلظت

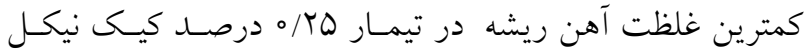

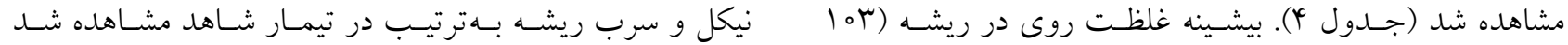




\begin{tabular}{|c|c|c|c|c|c|c|c|}
\hline \multicolumn{6}{|c|}{ ميانخين مربعات غلظت فلزات مختلف در ريشه } & \multirow{2}{*}{ درجه. } & \multirow{2}{*}{ تغنييرات } \\
\hline روى & سرب & نيكل & 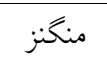 & آهن & 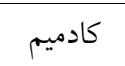 & & \\
\hline $149 V^{* *}$ & ro19*** & lorq"* & IYGY** & $1119^{* *}$ & $\Lambda Y \circ Y^{* * *}$ & 11 & تيمارها \\
\hline $\mathrm{V} / \mathrm{T} \Delta \wedge$ & ro/vaV & TV/TYL & MI & IV/OYY & D/AFV & щ & خطا \\
\hline \multicolumn{8}{|c|}{ ميانخين مربعات غلظت فلزات مختلف در برى } \\
\hline $1190^{* * *}$ & Irrs"* & rTor"* & $V \backslash Y^{* * *}$ & $k+10^{* * *}$ & $101 Y Y^{* * *}$ & 11 & تيمارها \\
\hline Q৭/QYV & $19 / 199$ & $r 9 / 991$ & $\mathrm{l} \wedge \mathrm{V}$ & $\Delta F / I r \Lambda$ & $r \Psi / \Delta \wedge \Delta$ & щ & خطا \\
\hline
\end{tabular}

رشد كَياه كاهو نشان مىدهد كه اخـتلاف معنسىدارى در سطحح

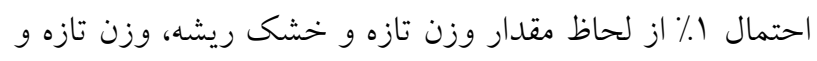

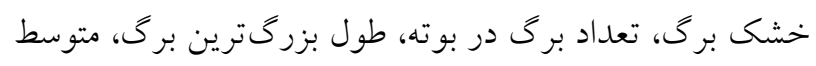

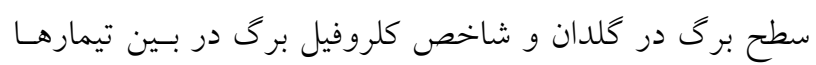
وجود دارد (جدول 9).

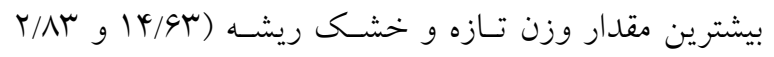

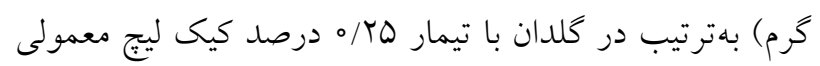

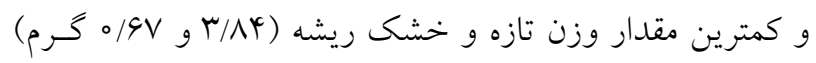

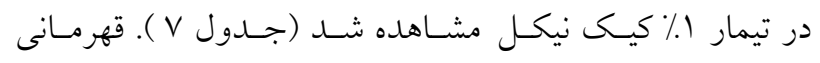
بير سلامى و همكاران (†) در يك آزمايش كلخانهاى، اثر كادميم

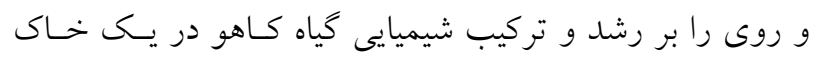

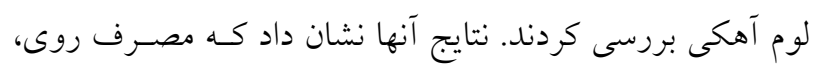

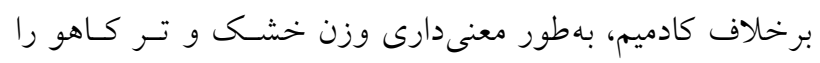

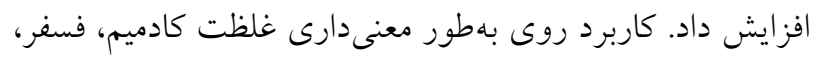

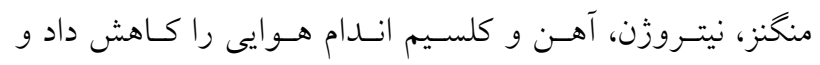
غلظت و جذب كل روى، مس و سديم را افزايش داد. افـزايش

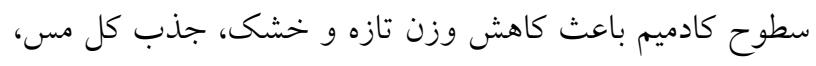

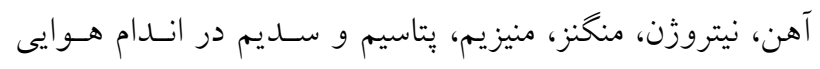

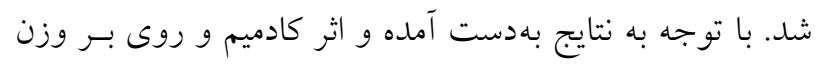

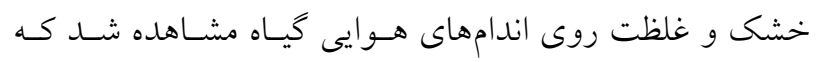
كاربرد روى توانست سبب كاهش اثر مضر كادميم بر رشد كيـاه كاهو شود. - ماردي كاهش رشد ريشه و بخش هوايى تحت تنش سرب مى توانـــ
(جدول Y). همجنين، مطابق اين جدول، بيشترين غلظت منگنـز

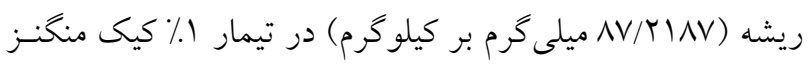

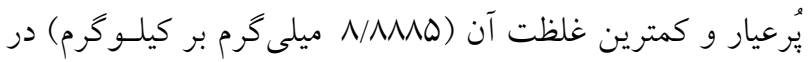

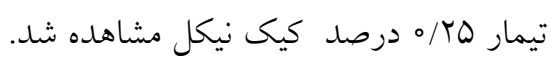

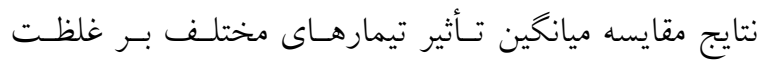

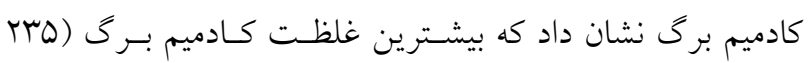

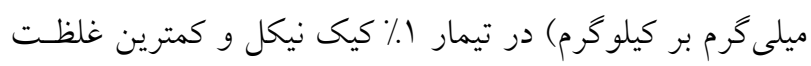

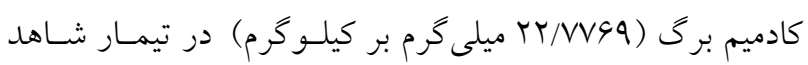

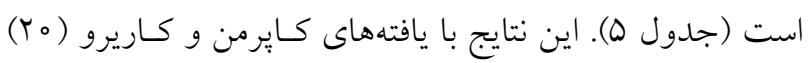

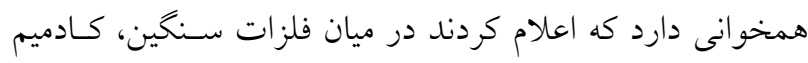

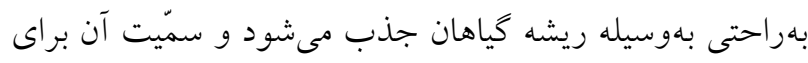
كياه تا مب برابر ساير فلزات سنخين است.

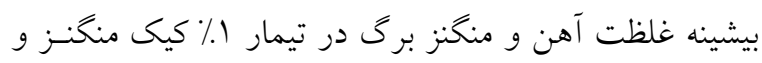

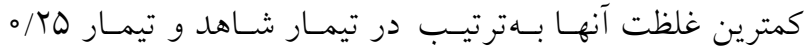

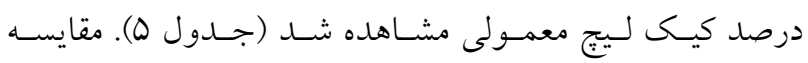

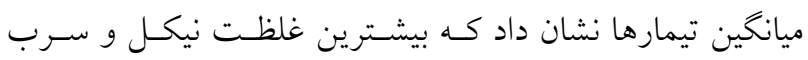

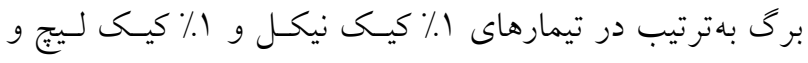

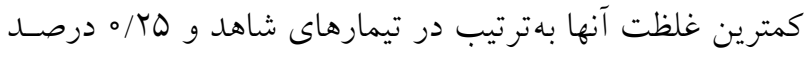

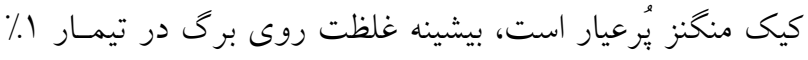

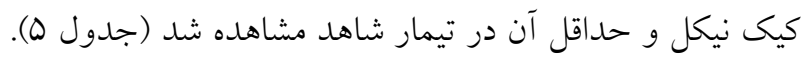

تأثير تيمارهاى مختلف بر شاخصهاى رشد گياه كاهو

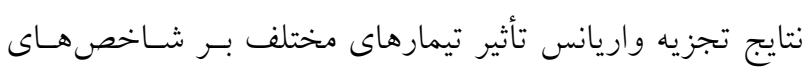


جدول Y. تأثير تيمارهاى مورد مطالعه بر غلظت عناصر در ريشه (ميلى كرم بر كيلوگرم)

\begin{tabular}{|c|c|c|c|c|c|c|c|}
\hline شاهد & كيك ليج & كيك منخُنز & كيك ليج معمولى & كيك منخنز يرعيار & 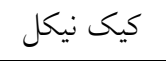 & كيك ليج برعيار & نوع سطح \\
\hline \multicolumn{8}{|c|}{ كادميم } \\
\hline \multirow[t]{4}{*}{$r / / 1 / r^{k}$} & & & & & & & $\circ$ \\
\hline & $r 1 / 990 \Lambda^{\mathrm{k}}$ & 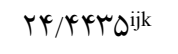 & TM/MTYkjk & $r \mu / \Lambda \wedge V q^{i j k}$ & $110^{c}$ & $r M / A \Lambda V q^{i j k}$ & $0 /$ TO \\
\hline & $Y \Psi / 999^{i j k}$ & $r q / ৭ 9 \wedge \wedge^{\mathrm{fgh}}$ & $Y Y^{\mathrm{F}} / 999^{\mathrm{ijk}}$ & rG/990\$ hji & $1 Y 4 b$ & 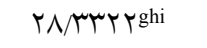 & $\circ / 0 \circ$ \\
\hline & TY/TY॰Qef & $Y V / T Y \circ r^{d}$ & $r \Psi / \Lambda \Lambda V Q^{e f}$ & ry/ykte & rmpa & $r G / 1 \circ 9 V^{e}$ & 1 \\
\hline \multicolumn{8}{|c|}{ آهن } \\
\hline & & & & & & & $\circ$ \\
\hline \multirow[t]{3}{*}{$r 9 / 9909 \mathrm{~g}$} & WV/VVGTf & $r 9 / 11 \circ 1 \mathrm{~g}$ & 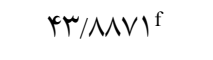 & $r y / 9999$ & $r$ r/ANVqg & $\mu \circ / \Delta Q Y \mu g$ & $\circ / T Q$ \\
\hline & $91 / 1 \circ \wedge V^{c d}$ & $\Delta Q / 99 \vee q^{d}$ & $\varphi \wedge / \mu \mu_{0} \varphi^{b c}$ & Yy/৭৭४ ref & FYAFYTVef & $91 / 1 \circ \wedge V^{c d}$ & $\circ / 0 \circ$ \\
\hline & $V \Lambda / T^{\prime} \circ r^{a}$ & $99 / 99 V Y^{b}$ & $\Delta \psi / 4+\|^{a}$ & $99 / 994 \mathrm{~cd}$ & $01 / 9949 \mathrm{e}$ & $V \Lambda / \mu T \circ r^{a}$ & 1 \\
\hline \multicolumn{8}{|c|}{ روى } \\
\hline \multirow{4}{*}{ TY/TYYIg } & & & & & & & $\circ$ \\
\hline & 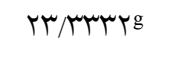 & $\mu y / 999 Y^{f f}$ & $r Y / 999 \wedge^{g}$ & $r \mu / \Lambda \Lambda V^{g}$ & $49 / 1101^{\mathrm{e}}$ & $m / / 1 \circ V^{f}$ & $\circ / T \Delta$ \\
\hline & $r \Delta / \Delta \Delta \omega r^{\mathrm{g}}$ & $\uparrow 4 / 9909 \mathrm{e}$ & $M T / Y Y I V^{f}$ & $M T / Y T I V^{f}$ & $99 / 1 \circ 9 \mu^{\mathrm{d}}$ & $49 / 1101^{\mathrm{e}}$ & $\circ / 0 \circ$ \\
\hline & 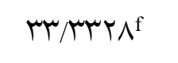 & $11 / 994 \mathrm{fb}$ & FY/MYrde & TY/TMITe & $1 \circ r^{\mathrm{a}}$ & $V Y / V V Q V^{c}$ & 1 \\
\hline \multicolumn{8}{|c|}{ نيكل } \\
\hline \multirow[t]{4}{*}{$9 / 9994 j$} & & & & & & & $\circ$ \\
\hline & $|Y / Y Y| V i j$ & $\wedge / \wedge \wedge \wedge \Delta^{j}$ & $\mu_{\circ / \Delta Q} \mu r_{f g}$ & 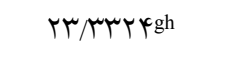 & $\mathrm{r} / / 990 \mathrm{fg}$ & $19 / 4$ crphi & $0 /$ TO \\
\hline & TY/FYrogh & TY/YYIYgh & $49 / 994 \wedge^{\mathrm{cd}}$ & $4 \backslash / / \circ 9 \Delta^{\mathrm{de}}$ & $\Delta \wedge / \Lambda \wedge \varsigma \Delta^{b}$ & $\mathrm{~m} / / \circ 99 \mathrm{fg}$ & $\circ / 0 \circ$ \\
\hline & $\uparrow Q / \Delta Q \Psi V^{c d e}$ & rq/990 ef & WV/WVAVa & $V q / 1 \circ \wedge 1^{a}$ & 1./DQYra & D1/9949bc & 1 \\
\hline \multicolumn{8}{|c|}{ سرب } \\
\hline \multirow[t]{4}{*}{${ }^{\Delta r} / \wedge \wedge \varphi V^{k}$} & & & & & & & $\circ$ \\
\hline & $৭ \wedge / \Lambda \wedge \& q^{\mathrm{fgh}}$ & $9 Y / ৭ 9 ૬ Y_{h i}$ & 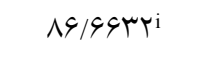 & $\Lambda \varphi / 1 \circ V^{i}$ & $V Y^{c} / 99 V^{j}$ & $99 / 99 \vee Y^{j}$ & $\circ / T \Delta$ \\
\hline & $11 Y^{\text {cde }}$ & $111^{\text {cde }}$ & $1 \circ \wedge^{\mathrm{def}}$ & $1 \circ \gamma^{e f g}$ & 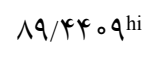 & $\Lambda \uparrow / 999 \varphi^{i}$ & $\circ / 0 \circ$ \\
\hline & $I V V^{a}$ & $1 K r^{b}$ & $119 \mathrm{bcd}$ & $119 \mathrm{cde}$ & $11 r^{\text {cde }}$ & $1111^{\mathrm{cde}}$ & 1 \\
\hline \multicolumn{8}{|c|}{ منكنز } \\
\hline \multirow[t]{4}{*}{$r \mu / M N q^{c}$ cde } & & & & & & & 。 \\
\hline & $|Y / T Y| V \mathrm{de}$ & Tr/WVGqcde & $|\circ / \Delta \Delta \Delta|^{\mathrm{de}}$ & 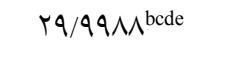 & $\Lambda / \Lambda \Lambda \wedge \Delta^{e}$ & $1 \% / M M \mu \mu^{d e}$ & $0 / T Q$ \\
\hline & $|V / V V V|^{\text {cde }}$ & $\nvdash / / \Delta \Delta \& q$ bcde & $1 Q / \Delta Q Y q \mathrm{de}$ & $01 / 1 \circ 91 \mathrm{bc}$ & $\mid r / \mu r \Lambda^{d e}$ & Tr/VVGq cde & $\circ / 0 \circ$ \\
\hline & $4 \backslash / / \circ ৭ \Delta^{\text {bcde }}$ & $G / / Y / 9 V^{a b}$ & Tr/MrYycde & $\wedge \mathrm{V} / \mathrm{r} \backslash \wedge \mathrm{V}^{\mathrm{a}}$ & 19/4krycde & $\uparrow Q / \Delta Q \Psi V b c d$ & 1 \\
\hline
\end{tabular}

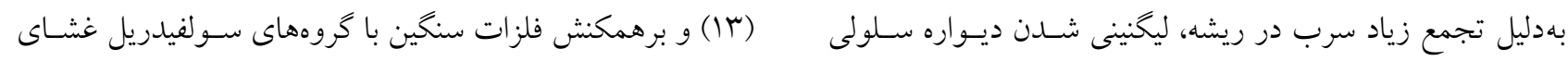

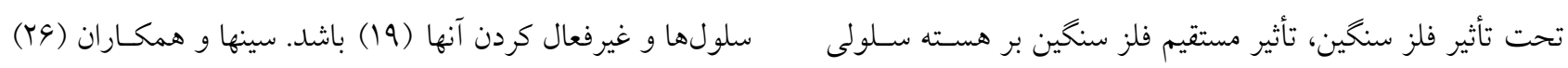


جدول ه. تأثير تيمارهاى مورد مطالعه بر غلظت عناصر در برگ (ميلى گرم بر كيلوگرم)

\begin{tabular}{|c|c|c|c|c|c|c|c|}
\hline شاهد & كيك ليج & كيك منكُز & كيك ليج معمولى & كيك منگنز يرعيار & كيك نيكل & كيك ليج برعيار & نوع سطح \\
\hline \multicolumn{8}{|c|}{ كادميوم } \\
\hline TYNVGQh & & & & & & & $\circ$ \\
\hline & TYAYrrogh & $M Y / \mathrm{TV} G Q^{\mathrm{efg}}$ & $r \Delta / \Delta Q Y \Delta^{g h}$ & TV/TYI/gh & $1 \circ r^{c}$ & 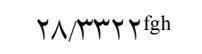 & $\circ / T \Delta$ \\
\hline & TV/YYl/gh & $r V / T Y \circ V^{e f}$ & rq/4krmfgh & rq/4xprfgh & $1 \wedge r^{b}$ & & $\circ / 0 \circ$ \\
\hline & r $/ 990$ refgh & $99 / 1 \circ \wedge \Delta^{\mathrm{d}}$ & $r Y / V V 9 Q^{\text {efg }}$ & $\Gamma T / V V G Q^{e}$ & $r M \Delta^{a}$ & 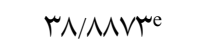 & 1 \\
\hline \multicolumn{8}{|c|}{ آهن } \\
\hline \multirow[t]{4}{*}{ T9/9909h } & & & & & & & $\circ$ \\
\hline & AV/VVAref & $q V / V V q^{\prime} q \mathrm{de}$ & $09 / 99 \vee 9 g$ & rV/VVGTh & rq/4krmh & $09 / 99 \vee 9 g$ & $\circ / T \Delta$ \\
\hline & $1 \circ \wedge^{\mathrm{cd}}$ & $1 \circ 9 \mathrm{~cd}$ & $q \wedge /$ rqqude & $49 / 1 \circ \wedge 0^{g}$ & $\Delta 9 / 1 \circ \wedge 9 \mathrm{~g}$ & $V \Lambda / \mu r \circ Y^{f}$ & $\circ / 0 \circ$ \\
\hline & lora & $191^{\mathrm{a}}$ & $1 q^{b}$ & $\vee q / 999 \Lambda^{f}$ & $V q / 4 \& I r^{f}$ & $111^{\mathrm{bc}}$ & 1 \\
\hline \multicolumn{8}{|c|}{ روى } \\
\hline \multirow[t]{4}{*}{$T^{m} / 1 / \circ V^{i}$} & & & & & & & $\circ$ \\
\hline & r4/994hi & $01 / 1 \circ 99^{\text {efgh }}$ & YY/VVGQ fghi & rN/AMMlghi & $\Delta V / T Y \circ V^{d e f}$ & $49 / 99 \wedge \Lambda^{\text {efgh }}$ & $\circ / T \Delta$ \\
\hline & $4 \& / 1101^{\text {efgh }}$ & Dq/4YYqde & $F V / V V G V$ efgh & $49 / 9909$ efgh & $\Lambda T / Y / 9 V^{b}$ & & $\circ / 0 \circ$ \\
\hline & $\uparrow ৭ / ৭ 9 \wedge \wedge^{\mathrm{efgh}}$ & $\mathrm{V} 9 / 99 \mathrm{fubc}$ & $\Delta V / T Y \circ V$ def & $49 / 99 \wedge \wedge^{\mathrm{efgh}}$ & $119^{a}$ & $q \mathrm{~V} / \mathrm{V} \Delta q_{\mathrm{cd}}$ & 1 \\
\hline \multicolumn{8}{|c|}{ 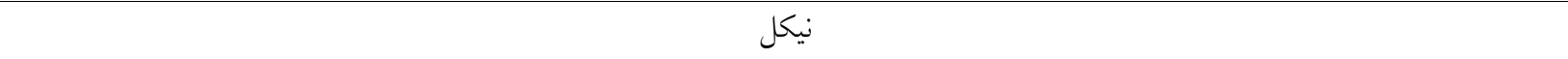 } \\
\hline \multirow[t]{4}{*}{ i } & & & & & & & $\circ$ \\
\hline & TY/ArTdk & $\mid r / A M \Lambda \mu^{i}$ & $\Delta V / N V \Delta \Delta^{g h}$ & Or/VVOVhi & $9 / / 1 \circ \wedge V^{g h}$ & TV/TYIIK & $\circ / T \Delta$ \\
\hline & KY/VVGIj & $\left\langle y / / \circ 9 \Delta^{j}\right.$ & VN/Tr。ץe & 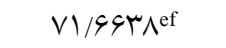 & $101 \mathrm{bc}$ & $99 / 1 \circ \wedge \Delta^{\mathrm{fg}}$ & $\circ / 0 \circ$ \\
\hline & $\Delta r / v V Q V^{h i}$ & $\uparrow V / V V \Delta Q^{i j}$ & $1 \circ 4 b$ & $q \psi / 4 \psi<V^{c d}$ & $1 r q^{a}$ & $\Lambda \Lambda / \Lambda \Lambda \Delta \mu^{\mathrm{d}}$ & 1 \\
\hline \multicolumn{8}{|c|}{ سرب } \\
\hline \multirow[t]{4}{*}{$\Delta Y / 99 \vee \Lambda^{\mathrm{hi}}$} & & & & & & & $\circ$ \\
\hline & $G \Lambda / M \wedge G l^{\text {ef }}$ & $\mathcal{F V / T Y} \circ \mu^{\mathrm{j} k}$ & $\left\langle 4 / 99 \wedge Y^{j k}\right.$ & rq/4rtqk & $K Y / Y Y \circ \Delta^{k}$ & $\mathrm{kr} / \Lambda \wedge V /^{\mathrm{k}}$ & $\circ / T \Delta$ \\
\hline & $\vee ৭ / ৭ ৭ ৭ \wedge^{\mathrm{cd}}$ & $V Q / \Delta Q T Q^{\text {de }}$ & GY/VVQrfgh & $\Delta Y / Y Y \circ l^{\mathrm{ij}}$ & OQ/KFY ghi & $91 / 1 \circ \wedge V^{\mathrm{fgh}}$ & $\circ / 0 \circ$ \\
\hline & $111^{\mathrm{a}}$ & $a r / r \backslash \wedge \Delta^{b}$ & $\wedge q / 44<\circ q^{b}$ & $q \Delta / \Delta \Delta q^{f} \mathrm{fg}$ & $\Lambda \varepsilon / \Lambda \circ \vee V b c$ & $\Lambda \mathrm{V} / \mathrm{T} \backslash \Lambda \mathrm{V}^{\mathrm{bc}}$ & 1 \\
\hline \multicolumn{8}{|c|}{ منغنز } \\
\hline \multirow[t]{4}{*}{$r \mathrm{Y} / 1.99 \mathrm{def}$} & & & & & & & $\circ$ \\
\hline & ro/DQYref & bl & $r Q / \Delta Q Y Q^{\mathrm{f}}$ & $\varphi \circ / \Delta \Delta r q$ cdef & TV/NVGVef & rV/VVG rf & $\circ / T \Delta$ \\
\hline & $\uparrow 4 / 944 \wedge^{\text {bcdef }}$ & $4 \backslash / 1 \circ \wedge V^{a b c}$ & rV/VVG Y cdef & 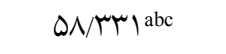 & $4 \backslash / 1 \circ 90^{\text {cdef }}$ & $\Delta r / M \wedge G \vee c d e f$ & $\circ / 0 \circ$ \\
\hline & $\Delta V / V V \Delta Q^{\mathrm{abcd}}$ & VG/9Grga & $M q / 4 Y Y q$ cdef & $V Q / \Delta \Delta r \Delta^{a}$ & 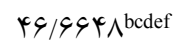 & $9 \mathrm{~V} / \mathrm{VQ} D \mid \mathrm{cdef}$ & 1 \\
\hline
\end{tabular}

كزارش كردند كه با افزايش سـطح سـرب در خـاك، عملكـرد و زيستتوده ريشـه و سـاقه و محتـواى كلروفيـل بـركهــاى گيـاه

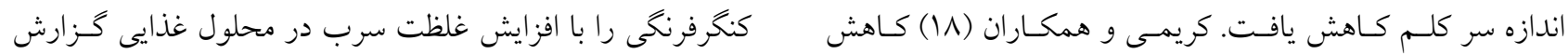


جدول و. نتايج تجزيه واريانس تأثير تيمارهاى مختلف بر شاخصهاى رشد و ميزان كلروفيل گياه كاهو

\begin{tabular}{|c|c|c|c|c|c|c|c|c|c|}
\hline \multicolumn{8}{|c|}{ ميانخين مربعات } & \multirow{4}{*}{ درازجه } & \multirow{4}{*}{ تغنير } \\
\hline \multicolumn{6}{|c|}{ برى } & \multicolumn{2}{|c|}{ ريشه } & & \\
\hline شاخص & متوسط سطح & طول بزرگترين & تعداد برى & وزن خشك & وزن تازه & وزن خشك & وزن تازه & & \\
\hline كلروفيل & برگ در گلدان & برى & در كلدان & & كلدان & كرم در & & & \\
\hline$r Q Q^{* * *}$ & $\Delta ৭ / \Delta \wedge r^{* *}$ & YY/AYV*** & $199^{* * *}$ & $\varphi Q / \Delta 10^{* * *}$ & MU人民"* & 1/०Y"*** & Tr/999"** & 11 & تيمارها \\
\hline$\circ / \circ \circ \Delta$ & $0 / 01 \mathrm{~V}$ & $\circ / T \circ r$ &.$/ 990$ & $r / T \mu r$ & $0 / 011$ & $0 / 011$ & ०/०YI & 山 & خطا \\
\hline
\end{tabular}

جدول V. تأثير سطوح مختلف كيك بر وزن تازه و خشك ريشه و برى (گرم در گلدان)

\begin{tabular}{|c|c|c|c|c|c|c|c|}
\hline شاهد & كيك ليج & كيك منخنز & كيك ليج معمولى & كيك منكنز يرعيار & كيك نيكل & كيك ليج يرعيار & نوع سطح \\
\hline \multicolumn{8}{|c|}{ وزن تازه ريشه } \\
\hline \multirow[t]{4}{*}{$11 / \mathrm{f}^{\mathrm{f}}$} & & & & & & & 。 \\
\hline & $14 / \circ \Delta^{b}$ & $\mid r / M \Lambda^{d}$ & $\mid y / 9 \mu^{a}$ & $\mid r / 9 V^{\mathrm{d}}$ & $9 / \mu \mu^{1}$ & $11 / 4 q^{f}$ & $\circ / T \Delta$ \\
\hline & $1 T / 9 Q^{\mathrm{d}}$ & $11 / 90^{f}$ & $|r / \mu|^{c}$ & $11 / 99^{\mathrm{e}}$ & $\Delta / \Gamma V^{1}$ & $11 / 1 \mathrm{~kg}^{\mathrm{g}}$ & $\circ / 0 \circ$ \\
\hline & $1 T / 19^{e}$ & $9 / \circ \mu^{\mathrm{j}}$ & $|\mu / \mu|^{c}$ & $1 \circ / V 1^{\mathrm{h}}$ & $r / \Lambda r^{m}$ & $\Lambda / V \mu^{\mathrm{k}}$ & 1 \\
\hline \multicolumn{8}{|c|}{ وزن خشك ريشه } \\
\hline \multirow[t]{4}{*}{$1 / 9 \wedge^{g}$} & & & & & & & $\circ$ \\
\hline & $r / \wedge^{\mathrm{a}}$ & $r / 4 I^{b}$ & $r / \wedge r^{\mathrm{a}}$ & $r / \mathcal{Y} \wedge^{\mathrm{b}}$ & $1 / 4 q^{h}$ & $r / 4 I^{b}$ & $\circ / T \Delta$ \\
\hline & $r / T^{\mathrm{cd}}$ & $r / \circ V^{\mathrm{de}}$ & $r / r V^{b c}$ & $r / \backslash \Lambda^{d}$ & $\circ / v q^{i}$ & $1 / 90^{\mathrm{ef}}$ & $\circ / 0 \circ$ \\
\hline & $r / \circ q^{\text {de }}$ & $1 / \mathrm{V} 9^{\mathrm{fe}}$ & $r / l^{\mathrm{de}}$ & $1 / 9 \wedge^{e}$ & $\circ / 9 V^{i}$ & $1 / \mu V^{h}$ & 1 \\
\hline \multicolumn{8}{|c|}{ وزن تازه برى } \\
\hline \multirow[t]{4}{*}{$\wedge q / 1^{i}$} & & & & & & & $\circ$ \\
\hline & $109^{b}$ & $৭ \diamond / \circ \wedge^{g}$ & $1.4^{b}$ & $110^{a}$ & rI/rro & $\Lambda \mathcal{Y} / Y V^{k}$ & $\circ / T Q$ \\
\hline & $104^{b}$ & $9 x / \mu y h$ & $104^{b}$ & $1 \circ 4^{b}$ & $V / Y Y^{p}$ & $\Lambda \circ / \circ \Delta^{1}$ & $\circ / 0 \circ$ \\
\hline & $\Lambda V / I r^{j}$ & $\mathrm{~V} / G \mathrm{Y}^{\mathrm{m}}$ & $99 / \pi \varphi^{\mathrm{f}}$ & $1 \circ \Delta^{\mathrm{e}}$ & $\varphi / 4 x q$ & $V \psi / \Lambda \psi^{n}$ & 1 \\
\hline \multicolumn{8}{|c|}{ وزن خشك برى } \\
\hline \multirow[t]{4}{*}{$1 \circ / \Delta \Lambda^{\mathrm{cd}}$} & & & & & & & $\circ$ \\
\hline & $\| r / 4 \varphi^{a b}$ & $\mid r / T V^{b c}$ & $\| \mu /\left.\Delta\right|^{a b}$ & $|r / 9|^{a}$ & $r /\left.\Lambda\right|^{e f}$ & 11/Rrabcd & $\circ / T \Delta$ \\
\hline & $11 / 90^{a b c}$ & $1 \circ / V \omega^{b c d}$ & $\left.|r /|\right|^{a b c}$ & $\mid r / \Delta \varphi^{a b c}$ & $1 / v q^{f}$ & $1 \circ / Y^{\mathrm{cd}}$ & $\circ / 0 \circ$ \\
\hline & $10 / 9 y^{\mathrm{cd}}$ & $10 / 1 y^{b c d}$ & $10 / 94 b c d$ & $\mid r / 4 \Delta^{a b c}$ & $1 / \mu 4^{f}$ & $\Lambda / q V^{d}$ & 1 \\
\hline
\end{tabular}




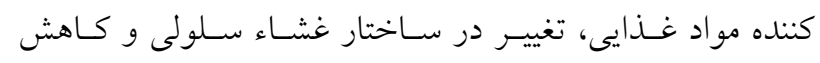

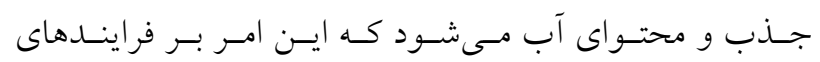

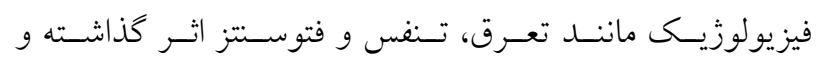

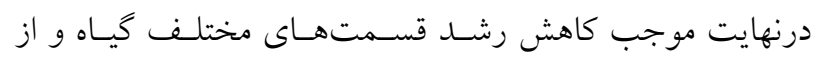

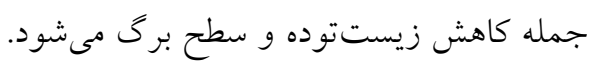

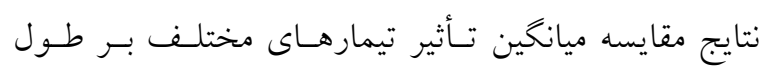

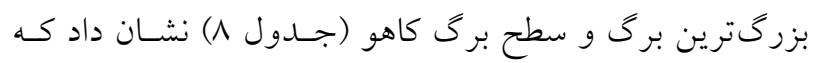

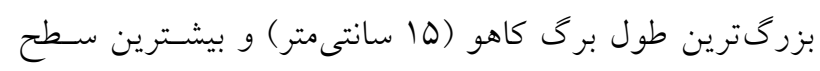

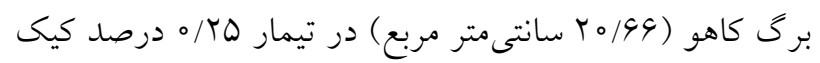

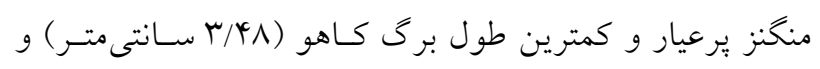

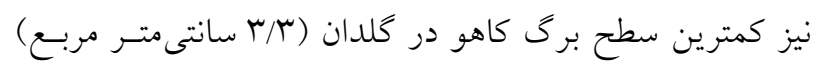

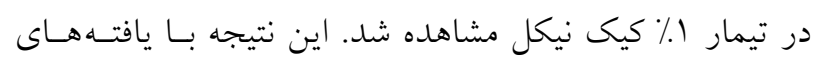

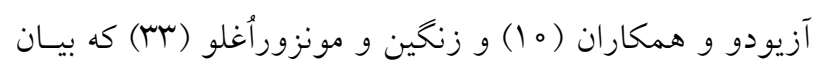

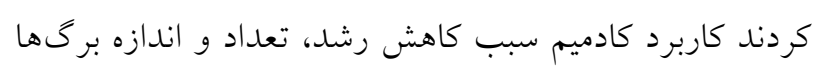

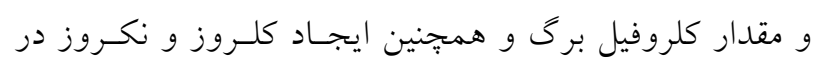
بر گهاى كياه آفتابكر دان شده هماهنكى دئ دارد.

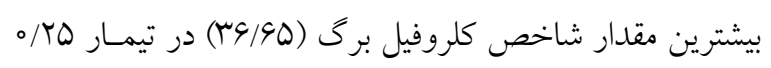

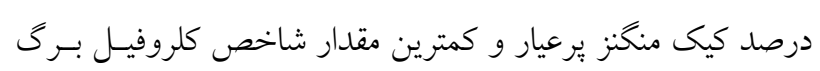

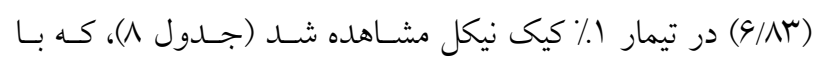

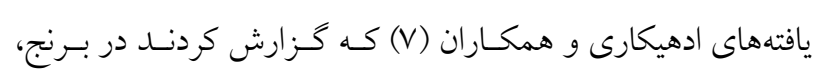

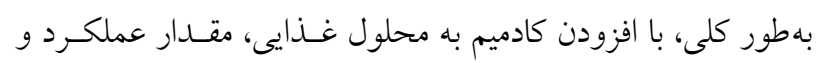
كلروفيل برگها كاهش يافت، همخوانى دارد.

\section{نتيجه گيرى}

در بررسى شش نوع كيى كارخانجات سـرب و روى مشـخص

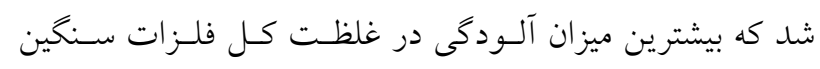

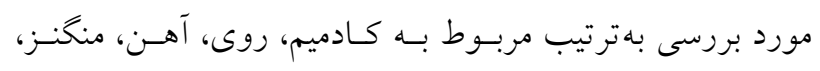
سرب و نيكل بوده و در غلظتهاى قابل جذب فلـزات سـنخين

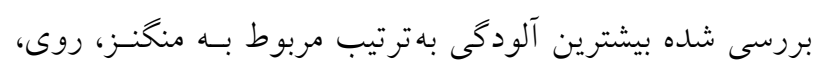

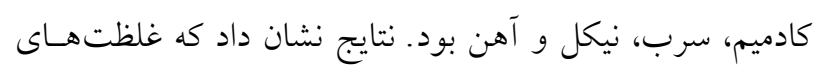

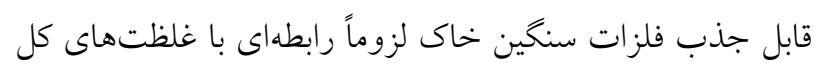

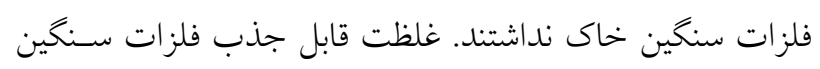

كردهاند. يُزوهش هاى انجام شده روى گونههـاى گيـاهى مختلـف

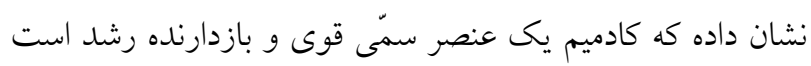

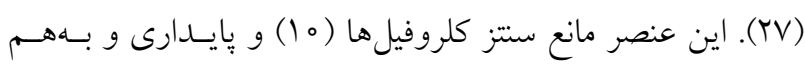

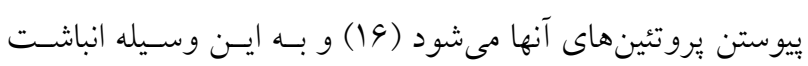

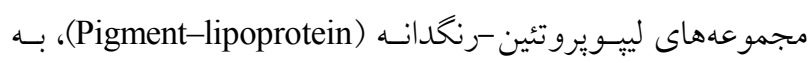

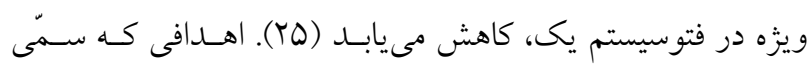

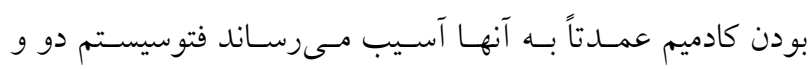
فازهاى آنزيمسى فتوسـتزي، ه- بيفسـفات كربوكسـيلاز / اكسيزناز (5-biphosphate carboxylase/oxygenase) (Ribulose-1)

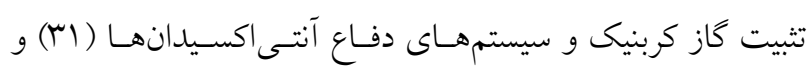

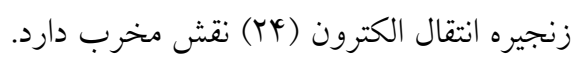

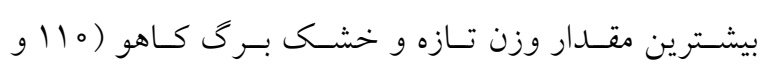
|r/q|

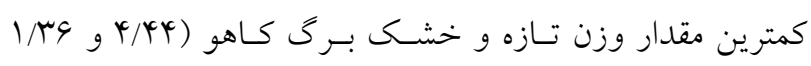

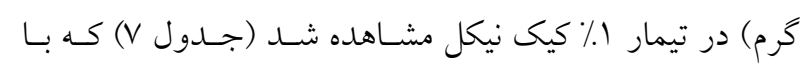

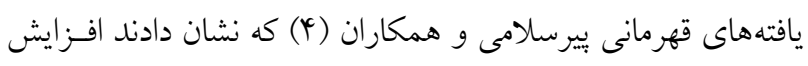

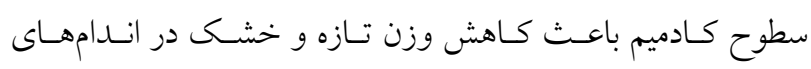

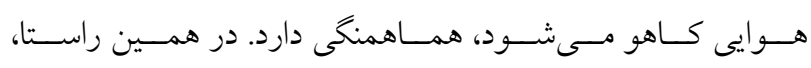

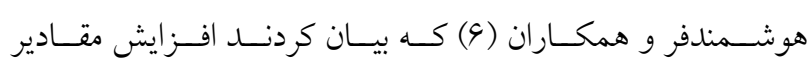

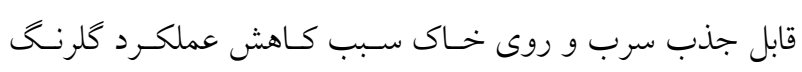

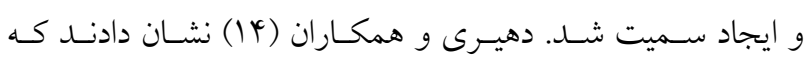
كادميم باعث كاهش معنى دار وزن خشك اندامهاى هـو ايى اسـفناج

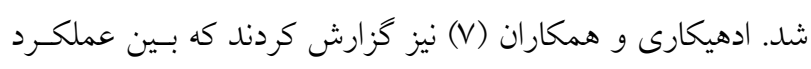

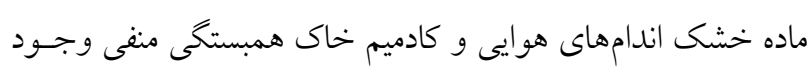
دارد.

بيشترين تعداد بـرى كـاهو در كلــدان (مه عـدد) در تيمـار

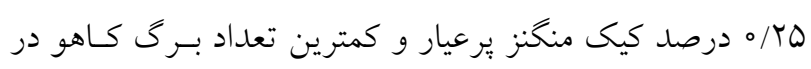

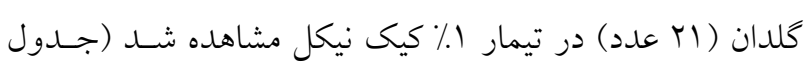

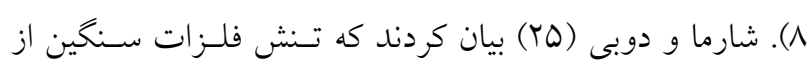

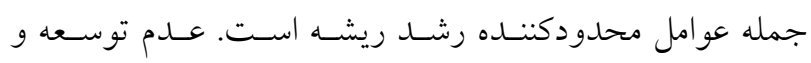

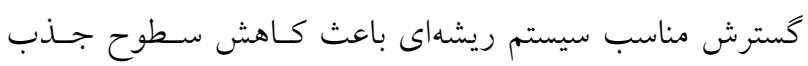


جدول ^. تأثير سطوح مختلف كيك بر شاخصهاى رشدى برى

\begin{tabular}{|c|c|c|c|c|c|c|c|}
\hline شاهد & كيك ليج & كيى منكنز & كيك ليج معمولى & كيك منخنز. يرعيار & كيك نيكل & كيك ليج يرعيار & نوع سطح \\
\hline \multicolumn{8}{|c|}{ تعداد برى } \\
\hline \multirow[t]{4}{*}{ Ylefg } & & & & & & & $\circ$ \\
\hline & $4 \wedge^{\mathrm{bc}}$ & kref & rqab & $Q \circ a$ & $\mu \mu_{k}$ & rqhi & $\circ / T Q$ \\
\hline & $r \Delta d$ & $\varphi^{f \mathrm{fg}}$ & $q V^{c}$ & $r V^{c}$ & $r \Delta^{\mathrm{i}}$ & $r^{\mathrm{ij}}$ & $\circ / 00$ \\
\hline & $r \circ g h$ & rqhi & $r \circ g h$ & kre & $r l^{\mathrm{m}}$ & $r \vee j$ & 1 \\
\hline \multicolumn{8}{|c|}{ طول برى (سانتىمتر) } \\
\hline \multirow[t]{4}{*}{$1 \% / \Delta^{\mathrm{de}}$} & & & & & & & $\circ$ \\
\hline & $1 \mathrm{r} / 99 \mathrm{de}$ & $1 \% / \Delta^{d e}$ & $|\varphi /| \xi_{\mathrm{bcd}}$ & $10^{\mathrm{a}}$ & $10 \mathrm{~h}$ & iref & $\circ / T Q$ \\
\hline & $1 \pi / 9^{\mathrm{de}}$ & Ir/Nrde & $\mid r / \Lambda r^{\mathrm{cde}}$ & $\mid \psi / N r^{\mathrm{ab}}$ & $V / \Lambda \kappa^{i}$ & $K / \Delta \mathrm{fg}$ & $\circ / 0 \circ$ \\
\hline & $|r /| y_{\text {ef }}$ & $\mid r / 0^{\mathrm{fg}}$ & $\mid r / \Delta^{\mathrm{de}}$ & $\mid \psi / q a b c$ & $r / \Psi \wedge j$ & $1 \mathrm{rg}$ & 1 \\
\hline \multicolumn{8}{|c|}{ سطح برى (سانتىمتر مربع) } \\
\hline \multirow[t]{4}{*}{$11 / 14 \mathrm{e}$} & & & & & & & $\circ$ \\
\hline & $11 / V \varphi^{d}$ & $10 / \wedge q^{f}$ & $1 T / \Delta 9^{c}$ & ro/99a & $Y / Q Y^{i}$ & $\Lambda / \Delta \Delta^{\mathrm{ij}}$ & $\circ / T Q$ \\
\hline & $9 / 11^{h}$ & $9 / 1^{\mathrm{h}}$ & $10 / r r^{2}$ & $19 / 49 \mathrm{~b}$ & $r / \wedge q^{m}$ & $\Lambda / N^{\kappa j}$ &.$/ 00$ \\
\hline & $\Lambda / 9 \Lambda^{i}$ & $V / I^{\mathrm{k}}$ & $N / q Y^{\mathrm{h}}$ & $11 / M^{d}$ & $\mu / \mu^{n}$ & $9 / 99 \mathrm{k}$ & 1 \\
\hline \multicolumn{8}{|c|}{ شاخص كلروفيل برى } \\
\hline \multirow[t]{4}{*}{$r q / \mu^{a}$} & & & & & & & $\circ$ \\
\hline & $r \Delta / \circ q^{c}$ & $r \Delta /\left.\circ\right|^{c}$ & $r \Delta / v q^{b}$ & $r 4 / 90^{a}$ & $I r / V^{m}$ & $\Gamma / \omega^{g}$ & $\circ / T Q$ \\
\hline & $r \mu / V f^{4 f}$ & $M / \Delta q_{g}$ & $\mu y / r \mu \mathrm{e}$ & $M Y / \Lambda l^{d}$ & $9 / \circ 4^{n}$ & $r \circ / \Lambda \Lambda^{j}$ & $\circ / 0 \circ$ \\
\hline & $M / / \Lambda r^{i}$ & $\mu \circ / \mu \mu^{k}$ & $\mu r / T^{h}$ & $\mu \mathrm{T} / \Delta V^{g}$ & g/Nro & $T V / Q T^{i}$ & 1 \\
\hline
\end{tabular}

خاكهاى تيمار شده با كيكها بر اثر جذب توسط كياه كاهو و مشـخص شــ كــه عناصـر كــادميم و نيكـل باعـث كــاهش

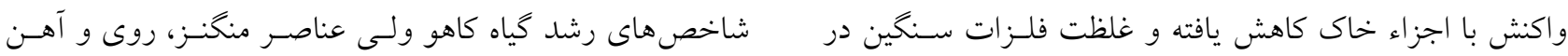

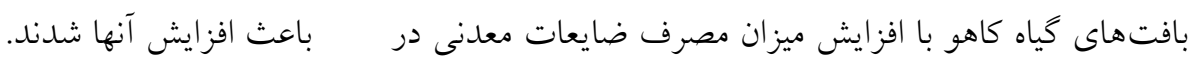
خاك افزايش يافت. در بررسى شاخص هـاى رشــ كيـاه كـاهو

\section{منابع مورد استفاده}

ا. خداوردى لو، ح. و م. همايى. عیبا. مدلسازى پالايش سبز خاكهاى آلوده به سرب وكادميم. علوم وفنون كشاورزى و منابع طبيعى HT ז. شرفبافى، ش. و ك. شهبازى. rوبا. اثر غلظت كادميم و سرب اضافه شده بر زيستفراهمى آنها در خاكهاى مختلف. 


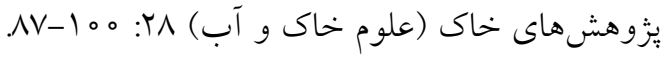

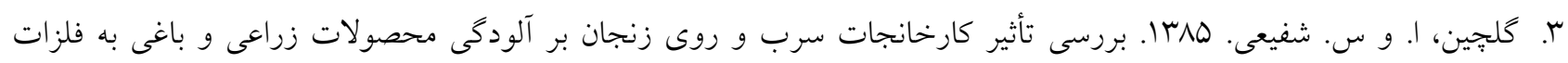

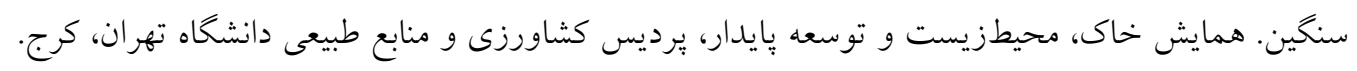

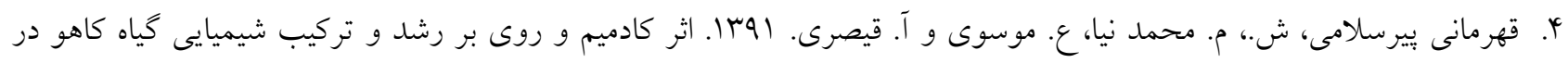

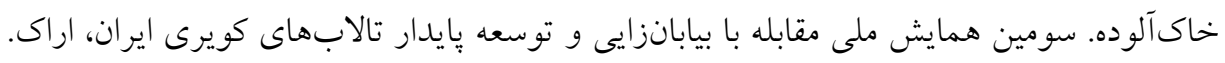

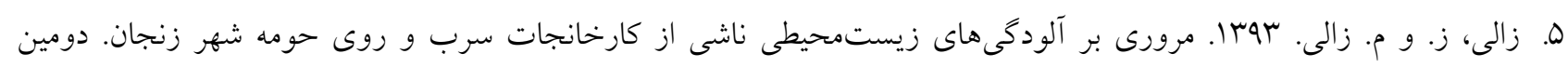

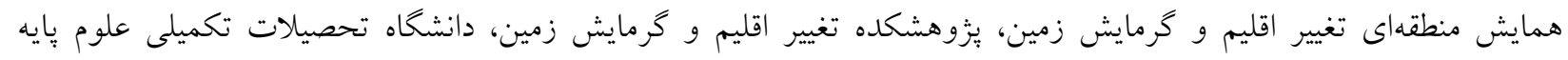

$$
\begin{aligned}
& \text { زنجان. }
\end{aligned}
$$

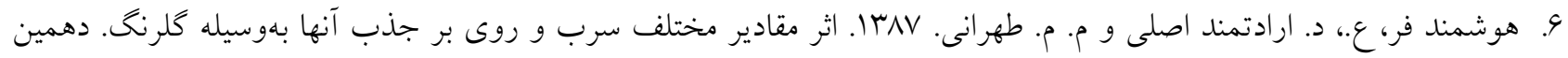

$$
\begin{aligned}
& \text { كنگره علوم زراعت و اصلاح نباتات، تهر ان. }
\end{aligned}
$$

7. Adhikari, T., T.O. Elisha, Y. Libal and M. Shenker. 2006. Effect of cadmium and iron on rice (Oryza sativa L.) plant in chelator-buffered nutrient solution. J. Plant Nutr. 29: 1919-1940.

8. Adiloglu, A. 2002. The effect of zinc application on uptake of cadmium in some cereal species. Arch. Agron. Soil Sci. 48: 553-556.

9. Alexander, P.D., B.L. Alloway and A.M. Dourado. 2006. Genotypic variations in the accumulation of $\mathrm{Cd}, \mathrm{Cu}, \mathrm{Pb}$ and $\mathrm{Zn}$ exhibited by six commonly grown vegetables. Environ. Pollut. 144: 736-745.

10. Azevedo, H.C., L. Gomes, J. Pinto, S.F. Loureiro and C. Santos. 2005. Cadmium effects on sunflower growth and photosynthesis. J. Plant Nutr. 28: 2211-2220.

11. Carter, M.R. 1993. Soil Sampling and Method of Analysis. CSSS, Lewis Publishers.

12. Chen, C., B. Zheng, X. Jiang, Z. Zhao, Y. Zhan, F. Yi and J. Ren. 2013. Spatial distribution and pollution assessment of mercury in sediments of Lake Taihu, China. J. Environ. Sci. 25(2): 316-325.

13. Daud, M.K., M.T. Variath, S. Ali, U. Najeeb, M. Jamil, Y. Hayat, M. Dawood, M.I. Khan, M. Zaffar, S.A. Cheema, X.H. Tong and S. Zhu. 2009. Cadmium-induced ultramorphological and physiological changes in leaves of two transgenic cotton cultivars and their wild relatives. J. Hazard Mater. 168: 614-625.

14. Dehiri, G. S., M. S. Brar and S. S. Malhi. 2007. Influence of phosphorus application on growth and cadmium uptake of spinach in two cadmium contaminated soils. J. Plant Nutr. 170: 495-499.

15. Hemphill, D.D. 1972. Availability of trace element to plants with respect to soil-plant interaction. Ann. N. Y. Acad. Sci. Vol. 199.

16. Horvath, G., M. Droppa, A. Oravecz, V.I. Raskin and J.B. Marder. 1996. Formation of the photosynthetic apparatus during greening of cadmium poisoned barley leaves. Plantar. 199: 238-244.

17. Kabata-Pendias, A. and H. Pendias. 1992. Trace Elements in Soils and Plants. Second edition, CRC Press, Inc., Boca Raton, Florida.

18. Karimi, N., M. Khanahmadi and B. Moradi. 2013. The effects of lead on some physiological parameters of artichoke. IJPP 20(1): 49-62.

19. Khudsar, T., M. Uzzafar, W.Y. Soh and M. Iqbal. 2000. Morphological and anatomical variations of Cajanus cajan (Linn. Huth) raised in cadmium-rich soil. J. Plant Biol. 43: 149-157.

20. Kuperman, R.G. and M.M. Carreiro. 1997. Soil heavy metal concentrations, microbial biomass and enzyme activities in a contaminated grassland ecosystem. Soil Biol. Biochem. 29(2): 179-190.

21. Martins, R.J., R. Pardo and R.A. Boaventura. 2004. Cadmium (II) and zinc (II) adsorption by the aquatic moss Fontinalis antipyretica: Effect of temperature, $\mathrm{pH}$ and water hardness. Water Res. 38(3): 693-699.

22. Mico, C., L. Recatala, M. Peris and J. Sanchez. 2006. Assessing heavy metal sources in agricultural soils of an European Mediterranean area by multivariate analysis. Chemosphere 65(5): 863-872.

23. Podar, D., M.H. Ramsey and M.J. Hutchings. 2004. Effect of cadmium, zinc and substrate heterogeneity on yield shoot metal concentration and metal uptake by Brassica Junicea: Implication for human health risk assessment and phytoremediation. New Phytol. 163: 313-324.

24. Sandalio, L.M., H.C. Dalurzo, M. Gomes, M. Romero-Puertas and L. Del Rio. 2001. Cadmium-induced changes in the growth and oxidative metabolism of pea plants. J. Exp. Bot. 52: 2115-2126.

25. Sharma, P. and R.S.H. Dubey. 2005. Lead toxicity in plants. Plant Physiol. 17: 35-52.

26. Sinha, P., B. Dube, P. Srivastava and C. Chatterjee. 2006. Alteration in uptake and translocation of essential 
nutrients in cabbage by excess lead. Chemosphere 65(4): 651-656.

27. Smiri, M., A. Chaoui and E. El Ferjani. 2009. Respiratory metabolism in the embryonic axis of germinating pea seed exposed to cadmium. Plant Physiol. 166(3): 259-269.

28. Smith, S.R. 2009. A critical review of the bioavailability and impacts of heavy metals in municipal solid waste composts compared to sewage sludge. Environ. Int. 35(1): 142-156.

29. Soumaré, M., F.M.G. Tack and M.G. Verloo. 2003. Characterisation of Malian and Belgian solid waste composts with respect to fertility and suitability for land application. Waste Manage. 23: 517-522.

30. Sparks, D.L., A.L. Page, P.A. Helmke, R.H. Loeppert, P.N. Soltanpour, M.A. Tabatabai and M.E. Sumner. 1996. Methods of Soil Analysis, Part 3, Chemical Methods, SSSA, Madison, WI.

31. Udita, G., K. Rajneesh Agnihotri, K. Ravinder and S. Rajendra. 2013. Effects of heavy metal Cd on some physiological and biochemical parameters of barley (Hordeum vulgare). IJACS 5(22): 2743- 2751.

32. Wubishet Gezahegan, W., A. Srinivasulu, B. Aruna, S. Banerjee, M. Sudarshan, P.V. Lakshmi Narayana and A.D.P. Rao. 2017. Study of heavy metals accumulation in leafy vegetables of Ethiopia. J. Environ. Sci. Toxicol. Food Technol. 11(5): 57-68.

33. Zengin, F.K. and O. Munzuroglu. 2006. Toxic effect of cadmium $(\mathrm{Cd}++)$ on metabolism of sunflower (Heliantus annus L.) seedlings. Acta Agr. Scand. 56: 224-229.

34. Zheljazkov, V.D. and P.R. Warman. 2004. Phytoavailability and fractionation of copper, manganese and zinc in soil following application of two composts to four crops. Environ. Pollut. 131: 187-195. 


\title{
Evaluation of Uptake and Accumulation of Heavy Metals by Lettuce in Soil Treated with Inorganic Wastes of Lead and Zinc Factories
}

\author{
Z. Rajabi ${ }^{1}$, P. Alamdari ${ }^{*}$ and A. Golchin ${ }^{1}$
}

(Received: 24 June 2018 ; Accepted: 9 January 2019)

\begin{abstract}
The lead-zinc industries are known to be one of the high-risk industries in terms of the environmental issues. In this research, 15 samples of waste (cake) from Zanjan Lead and Zinc Factory were collected and six samples were selected for adding to soil according to type and concentration of heavy metals. Then, lettuce was planted in soil samples treated with different cakes. After harvesting the plants, the plant growth indices, concentration of heavy metals in plant roots and leaves, and available concentration of heavy metals in the cultivated soil were measured. This research was carried out as a completely randomized design, in which, six types of cakes were tested at three levels $(0.25,0.5$ and $1 \%)$ with three replicates and three control samples (without adding the cakes). Results indicated that the highest amount of pollution for total concentration of heavy metals was related to $\mathrm{Cd}(168333 \mathrm{mg} / \mathrm{kg}), \mathrm{Zn}(100000 \mathrm{mg} / \mathrm{kg}), \mathrm{Fe}(91666$ $\mathrm{mg} / \mathrm{kg}), \mathrm{Mn}(25566 \mathrm{mg} / \mathrm{kg}) \mathrm{Pb}(13483 \mathrm{mg} / \mathrm{kg})$ and $\mathrm{Ni}(7966 \mathrm{mg} / \mathrm{kg})$, and for available concentration of heavy metals was related to $\mathrm{Mn}(21400 \mathrm{mg} / \mathrm{kg}), \mathrm{Zn}(16400 \mathrm{mg} / \mathrm{kg}), \mathrm{Cd}(4520 \mathrm{mg} / \mathrm{kg}), \mathrm{Pb}(2371 \mathrm{mg} / \mathrm{kg}), \mathrm{Ni}(194 \mathrm{mg} / \mathrm{kg})$ and $\mathrm{Fe}(11.2$ $\mathrm{mg} / \mathrm{kg}$ ). Available concentration of heavy metals in soils treated with cakes was reduced by uptake of these metals by lettuce.
\end{abstract}

Keywords: Zinc and lead factories' wastes, Heavy metals, Cake, Availability.

* Corresponding Author, Email: p_alamdari@znu.ac.ir 